\title{
Active Polycondensation of Monomers Having Hetero Atoms
}

\author{
Naoya Ogata, Yoshikazu Hosoda, and Goro Suzuki \\ Department of Chemistry, Sohpia University, Chiyoda-ku, Tokyo, Japan.
}

(Received March 9, 1974)

\begin{abstract}
Diesters having hetero atoms such as oxygen or sulfur atoms at position $\alpha$ to the carbonyl group of the ester underwent a polycondensation reaction with diamines to form a polyamide under mild conditions in solution. The reactivity enhancement due to the introduction of $\alpha$-hetero atoms in the esters could be arranged in the same order as that of the effect of $\beta$-hetero atoms: $-\mathrm{O}->-\mathrm{S}->=\mathrm{N}-$. The enhancement effect of $\alpha$-hetero atoms was superior to that of $\beta$-hetero atoms. On the other hand, the introduction of hetero atoms at position $\beta$ to amino group retarded the polycondensation reaction with ordinary esters. The effect of hetero atoms on the reactivity of esters was discussed.
\end{abstract}

KEY WORDS Polycondensation / Diester / Diamine / $\alpha$-Hetero

Atoms / Piperazine / Ether / Thioether /

It was reported in a previous paper $^{1}$ that diesters or dibasic acids having hetero atoms such as oxygen or sulfur atoms in the position $\beta$ to the carbonyl group underwent a polycondensation reaction with diamines to form a polyamide under such mild conditions that the polycondensation proceeded even at room temperature without eliminating by-products such as water from the reaction system.

The active polycondensation proceeded even in methanol solution, provided that methyl esters were used as monomers, indicating that the equilibrium of the polycondensation was favorably shifted towards the polymer formation side. The reactivity enhancement due to the introduction of $\beta$-hetero atoms in the diesters could be arranged in the following order: $-\mathrm{O}->-\mathrm{S}->=\mathrm{N}->-\mathrm{SO}_{2}->=\mathrm{P}-$.

The effect of these hetero atoms on the reactivity of diesters was assumed to be due to the intramolecular interaction between the hetero atoms and the carbonyl group of the diester. This paper is the further extension of studies on the effect of hetero atoms on the reactivity of ester or amine components. Various esters or amines having hetero atoms were synthesized and their reactivities towards polycondensation were investigated.

\section{EXPERIMENTAL}

\section{Synthesis of Monomers}

Model compounds. Various esters having oxygen, sulfur or nitrogen atoms at the position $\alpha$ to the carbonyl group of the ester were prepared by the reaction of the corresponding alcohol, mercaptan or amine with methyl monochloroacetate in tetrahydrofuran (THF) in the presence of an equimolar amount of triethylamine.

Various esters having $\beta$-hetero atoms were synthesized by the addition reaction of alcohol, mercaptan or amine with methyl acrylate in THF.

$$
\begin{aligned}
& \mathrm{R}-\mathrm{X}-\mathrm{H}+\mathrm{ClCH}_{2} \mathrm{COOCH}_{3} \\
& \mathrm{THF} \mathrm{R}-\mathrm{X}-\mathrm{CH}_{2} \mathrm{COOCH}_{3} \\
& \underset{\mathrm{Et} \mathrm{N}_{3} \mathrm{~N}}{\mathrm{R}-\mathrm{X}-\mathrm{H}+\mathrm{CH}_{2}=\mathrm{CHCOOCH}_{3}} \\
& \longrightarrow \mathrm{R}-\mathrm{X}-\mathrm{CH}_{2} \mathrm{CH}_{2} \mathrm{COOCH}_{3} \\
& \mathrm{X}:-\mathrm{O}-,-\mathrm{S}-,-\underset{\mathrm{N}}{\longrightarrow}
\end{aligned}
$$

Yields and boiling points of the resulting products are summarized in Table I.

Commercially available 2-ethoxyethylamine was used. 2-Aminoethyl-n-propyl thioether was synthesized from $n$-propyl mercaptan and ethyleneimine in ethanol. 
Active Polycondensation

Table I. Synthesis of model compounds

\begin{tabular}{llcc}
\hline Starting material & \multicolumn{1}{c}{ Model compound } & Yield, $\%$ & bp, ${ }^{\circ} \mathrm{C}$ \\
\hline $\mathrm{CH}_{3} \mathrm{CH}_{2} \mathrm{CH}_{2} \mathrm{OH}$ & $\mathrm{CH}_{3} \mathrm{CH}_{2} \mathrm{CH}_{2} \mathrm{OCH}_{2} \mathrm{COOCH}_{3}$ & 69 & $70-73 / 13 \mathrm{mmHg}$ \\
$\mathrm{CH}_{3} \mathrm{OH}$ & $\mathrm{CH}_{3} \mathrm{OCH}_{2} \mathrm{CH}_{2} \mathrm{COOCH}_{3}$ & 78 & $143-145$ \\
$\mathrm{CH}_{3} \mathrm{CH}_{2} \mathrm{CH}_{2} \mathrm{SH}$ & $\mathrm{CH}_{3} \mathrm{CH}_{2} \mathrm{CH}_{2} \mathrm{SCH}_{2} \mathrm{COOCH}_{3}$ & 78 & $88-90 / 15 \mathrm{mmHg}$ \\
$\mathrm{CH}_{3} \mathrm{CH}_{2} \mathrm{CH}_{2} \mathrm{SH}$ & $\mathrm{CH}_{3} \mathrm{CH}_{2} \mathrm{CH}_{2} \mathrm{SCH}_{2} \mathrm{CH}_{2} \mathrm{COOCH}_{3}$ & 65 & $140-143 / 13 \mathrm{mmHg}$ \\
$-\mathrm{NH}$ & $-\mathrm{NCH}_{2} \mathrm{CH}_{2} \mathrm{COOCH}_{3}$ & 64 & $100 / 17 \mathrm{mmHg}$ \\
$\mathrm{CH}_{3} \mathrm{CH}_{2} \mathrm{OH}$ & $\mathrm{CH}_{3} \mathrm{CH}_{2} \mathrm{OCH}_{2} \mathrm{CH}_{2} \mathrm{NH}_{2}$ & - & 108 \\
$\mathrm{CH}_{3} \mathrm{CH}_{2} \mathrm{CH}$ & $\mathrm{CH}_{3} \mathrm{CH}_{2} \mathrm{CH}_{2} \mathrm{SCH}_{2} \mathrm{CH}_{2} \mathrm{NH}_{2}$ & 61 & $40 / 3 \mathrm{mmH}^{-}$ \\
\hline
\end{tabular}

$$
\mathrm{C}_{3} \mathrm{H}_{7} \mathrm{SH}+\underbrace{\mathrm{CH}_{2}-\mathrm{CH}_{2}}_{\mathrm{NH}} \longrightarrow \mathrm{C}_{3} \mathrm{H}_{7} \mathrm{SCH}_{2} \mathrm{CH}_{2} \mathrm{NH}_{2}
$$

\section{Monomers}

4, 4'-Dihydroxydiphenyl-2, 2' -propane- $O, O^{\prime}$-diacetate (monomer $\alpha$-O) was prepared from bisphenol-A and methyl monochloroacetate. To a $100-\mathrm{m} l$ THF solution of bisphenol-A $(22 \mathrm{~g})$ was slowly added $4.8 \mathrm{~g}$ of sodium hydride and then $21.6 \mathrm{~g}$ of methyl monochloroacetate in 50 $\mathrm{m} l$ of THF with stirring. The solution was stirred for an additional $4 \mathrm{hr}$ at room temperature and the THF was evaporated off after the filtration of sodium chloride. The residual oil was distilled in vacuo. Yield $29 \%$, bp $160^{\circ} \mathrm{C} / 2$ $\mathrm{mmHg}$; C, 67.84\% (67.71); H, 6.80\% (6.52).<smiles>CCOC(=O)CCCCCCCCCC(=O)Oc1ccc(C(C)(C)c2ccc(O)cc2)cc1</smiles>

resorcinol and methyl monochloroacetate. Yield $68 \%$, bp $165^{\circ} \mathrm{C} / 10 \mathrm{mmHg} ; \mathrm{C}, 47.52 \%$ (47.48); $\mathrm{H}, 4.65 \%$ (4.61).

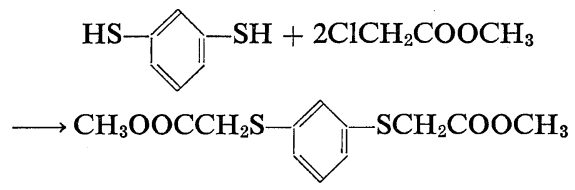

Piperazine- $N, N^{\prime}$-diacetate (monomer $\alpha-\mathrm{N}_{1}$ ) was synthesized from piperazine and methyl monochloroacetate. To a $100-\mathrm{m} l$ THF solution containing $8.6 \mathrm{~g}$ of piperazine and $20.1 \mathrm{~g}$ of triethylamine was added $20.6 \mathrm{~g}$ of methyl monochloroacetate in $50 \mathrm{ml}$ of THF and the solution was stirred for one day at room temperature. After filtering triethylammonium salt, the solution was distilled under reduced pressure. Yield $45 \%$, bp $152^{\circ} \mathrm{C} / 15 \mathrm{mmHg}, \mathrm{mp} 105^{\circ} \mathrm{C}$; C, $52.05 \%$
1,2-Ethanedithiol-S, $S^{\prime}$-diacetate (monomer $\alpha$ $S_{1}$ ) was obtained by the reaction of ethane dithiol with methyl monochloroacetate. A portion of $9.4 \mathrm{~g}$ of ethane dithiol was dissolved in $100 \mathrm{ml}$ of THF in the presence of $20.1 \mathrm{~g}$ of triethylamine. To this solution was added $21.1 \mathrm{~g}$ of methyl monochloroacetate in $50 \mathrm{~m} l$ of THF with stirring. After one day the solution was distilled in vacuo. Yield $49 \%$, bp $165^{\circ} \mathrm{C} / 20$ $\mathrm{mmHg}$; C, 40.30\% (40.34); H, 5.62\% (5.89).

$$
\stackrel{\mathrm{HSCH}}{\longrightarrow} \mathrm{CH}_{2} \mathrm{SH}+2 \mathrm{CHCH}_{3} \mathrm{OOCCH}_{2} \mathrm{SCH}_{2} \mathrm{CH}_{2} \mathrm{SCH}_{2} \mathrm{COOCH}_{3}
$$

Synthesis of dithioresorcinol-S, $S^{\prime}$-diacetate (monomer $\alpha-\mathrm{S}_{2}$ ) was carried out in a similar way to the synthesis of $\alpha-S_{1}$ by using dithio-<smiles>COC(=O)COc1ccc(C(C)(C)c2ccc(OCC(=O)OC)cc2)cc1</smiles(52.17); H, 7.90\% (7.82); N, $12.11 \%$ (12.17).

$$
\longrightarrow \mathrm{CH}_{3} \mathrm{OOCCH}_{2} \mathrm{~N}^{\prime} \mathrm{NCH}_{2} \mathrm{COOCH}_{3}
$$

Synthesis of $N, N^{\prime}$-dimethylethylenediamine- $N$, $N^{\prime}$-diacetate (monomer $\alpha-\mathrm{N}_{2}$ ) was carried out in a similar way to the synthesis of $\alpha-\mathrm{N}_{1}$. Yield $37 \%$; C, 47.11\% (47.07); H, 7.84\% (7.84); N, $13.50 \%$ (13.53).

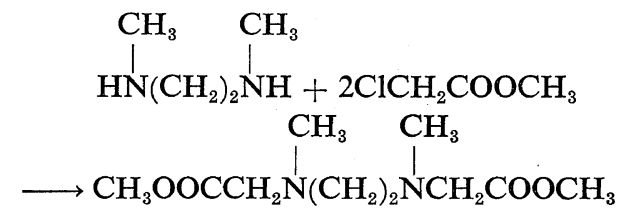

\section{Condensation Reactions}

Model Reactions. Equilmolar amounts of the 
model compounds described in Table $I$ were reacted with $n$-butylamine in methanol, THF or dimethyl sulfoxide (DMSO) under given conditions. Amines having $\beta$-hetero atoms were also reacted with acetate or caproate under given conditions. The condensation reaction was followed by titrating residual amines with $0.1-N$ $\mathrm{HCl}$ solution.

Polycondensation. Equimolar amounts of synthesized diesters and hexamethylenediamine (HMD) were dissolved in methanol or THF in the concentration of $1 \mathrm{~mol} / l$ in the presence of $1 \mathrm{~mol} \%$ of lithium methoxide as a catalyst. The solution was kept at a constant temperature for a given period. The polycondensation rates were determined by titrating residual $\mathrm{HMD}$ in the solution with $0.1-N \mathrm{HCl}$. Polymers were recovered by pouring the solution into acetone, followed by filtration and drying.

Bulk polycondensation was carried out in sealed tubes at 60 or $100^{\circ} \mathrm{C}$ and the product was repeatedly washed with acetone and weighed after drying. All polymers were identified by elemental and infrared analyses and solution viscosities were measured in $m$-cresol in the concentration of $1 \%$ at $30^{\circ} \mathrm{C}$.

\section{RESULTS AND DISCUSSION}

\section{Model Reactions}

The condensation reaction of propoxyacetate, propylthioacetate or piperazine- $N$-acetate with $n$-butylamine was carried out in either methanol or THF at $30^{\circ} \mathrm{C}$ and the results are shown in Figure 1. It was found that propoxyacetate easily underwent a faster condensation reaction than caproate which is an ordinary ester. The reactivity enhancement due to the introduction of $\alpha$-hetero atoms in the ester could be arranged in the following order: $\alpha-\mathrm{O}>\alpha-\mathrm{S}>\alpha-\mathrm{N}>$ none. Figure 2 shows results of the condensation reaction of esters having hetero atoms at position $\beta$ to the carbonyl group. The similar enhancement effect due to hetero atoms on the condensation reaction of esters was observed. Comparing Figure 1 with Figure 2, it is seen that the enhancement effect of hetero atoms at position $\alpha$ to the carbonyl group was much superior to that of $\beta$-hetero atoms. The condensation reaction proceeded rapidly in methanol, while in THF the reaction occured with a much slower rate. Since methanol was a leaving product as a result of the condensation reaction when methyl ester was used, it seems to be curious in an equilibrium sense that the condensation reaction occurred rapidly even in methanol. It is assumed that the condensation reaction of the esters having $\alpha$ - or $\beta$-hetero atoms may have an ionic character which is involved at the intermediate reaction stage where a nucleophilic attack of the amine to the ester carbonyl group takes place. Therefore, the polar effect of solvents might be predominant.

Condensation reactions of amine having oxygen or sulfur atoms at position $\beta$ to amino group occurred slowly with ester in methanol as indicated in Figure 3. In spite of the fact that hetero atoms in the skeleton structure of esters enhanced the reactivity of the ester with the amine, the introduction of hetero atoms to the amine somewhat retarded the condensation reaction with ordinary esters. Particularly in THF the condensation reaction did not take place at $30^{\circ} \mathrm{C}$.

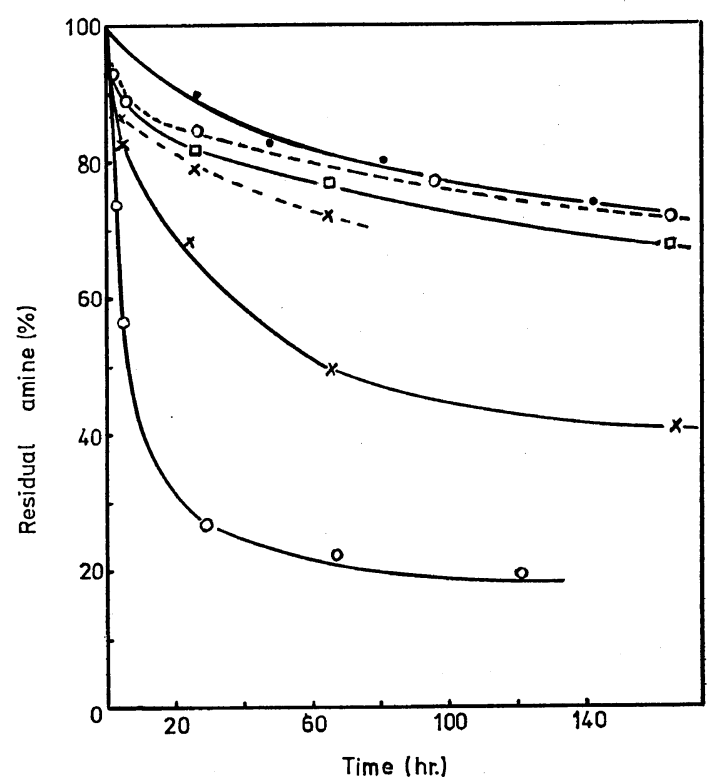

Figure 1. Model reactions of various methyl esters having $\alpha$-hetero atoms with $n$-butylamine: $\bigcirc$, propoxyacetate; $\times$, propylthioacetate; $\bigcirc$, piperazine- $N$-acetate; $\square$, caproate; --, in THF; - in methanol; temp, $30^{\circ} \mathrm{C}$; concn, $1 \mathrm{~mol} / l$. 
Active Polycondensation

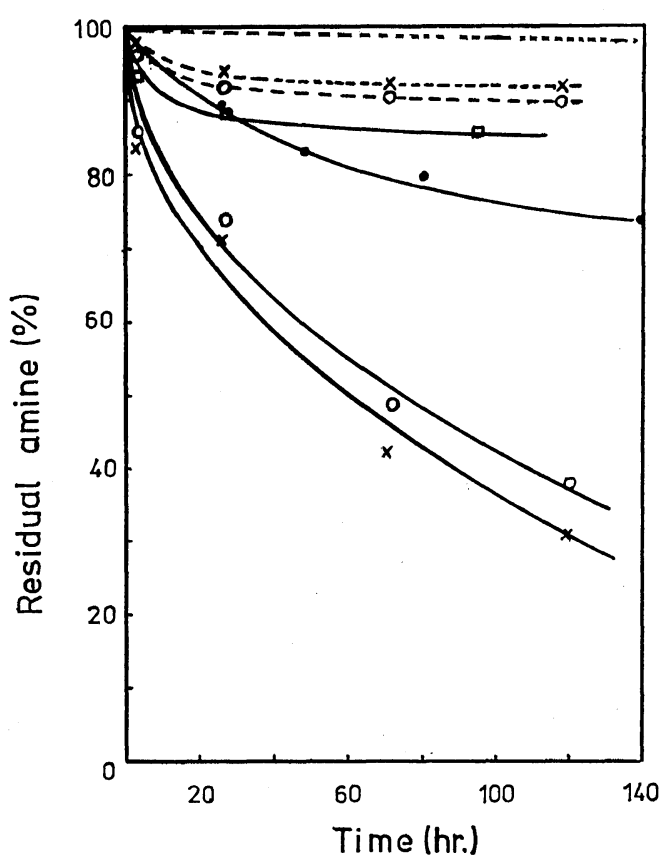

Figure 2. Model reactions of various esters having $\beta$-hetero atoms with $n$-butylamine: $\times, \mathrm{C}_{3} \mathrm{H}_{7^{-}}$ $\mathrm{SCH}_{2} \mathrm{CH}_{2} \mathrm{COOCH}_{3} ; \mathrm{O}, \mathrm{C}_{2} \mathrm{H}_{5} \mathrm{OCH}_{2} \mathrm{CH}_{2} \mathrm{COOCH}_{3}$;

$\square,\left\langle\mathrm{NCH}_{2} \mathrm{CH}_{2} \mathrm{COOCH}_{3} ;-\right.$, methyl caproate; --, in THF; -, in methanol; temp, $30^{\circ} \mathrm{C}$; concn, $1 \mathrm{~mol} / \mathrm{l}$.

\section{Polycondensation Reaction}

Polycondensation reaction of $\alpha-\mathrm{O}$ with HMD was carried out in methanol or THF at $30^{\circ} \mathrm{C}$ and results are shown in Figure 4 , which indicates that the polycondensation reaction occurred more rapidly in methanol than in THF and the reaction reached an apparent equilibrium in methanol within $5 \mathrm{hr}$. The same effect of solvents on the polycondensation was observed as in the case of the model reaction.

Results of the polycondensation reaction of $\alpha-S_{1}$ or $\alpha-S_{2}$ with HMD in DMSO or THF are indicated in Figure 5. A marked solvent effect on the polycondensation reaction was observed and the polycondensation of $\alpha-S_{2}$ proceeded more rapidly in DMSO than in THF. $\alpha-\mathrm{S}_{2}$, which has an aromatic nucleus, underwent the polycondensation more rapidly than $\alpha-\mathrm{S}_{1}$ which is an aliphatic thioether ester. By comparing Figure 4 with Figure 5, both $\alpha-S_{1}$ and $\alpha-S_{2}$ had a much inferior reactivity to $\alpha-\mathrm{O}$.

Figure 6 shows results of the polycondensation of $\alpha-\mathrm{N}_{2}$ with HMD in methanol or THF at 30 or $60^{\circ} \mathrm{C}$. It is seen in Figure 6 that methanol accelerated the polycondensation more rapidly than THF, just as the polycondensation of $\alpha-\mathrm{O}$ and $\alpha-\mathrm{S}$. Among the diesters having $\alpha$-hetero atoms, $\alpha-\mathrm{N}_{2}$ had the worst reactivity

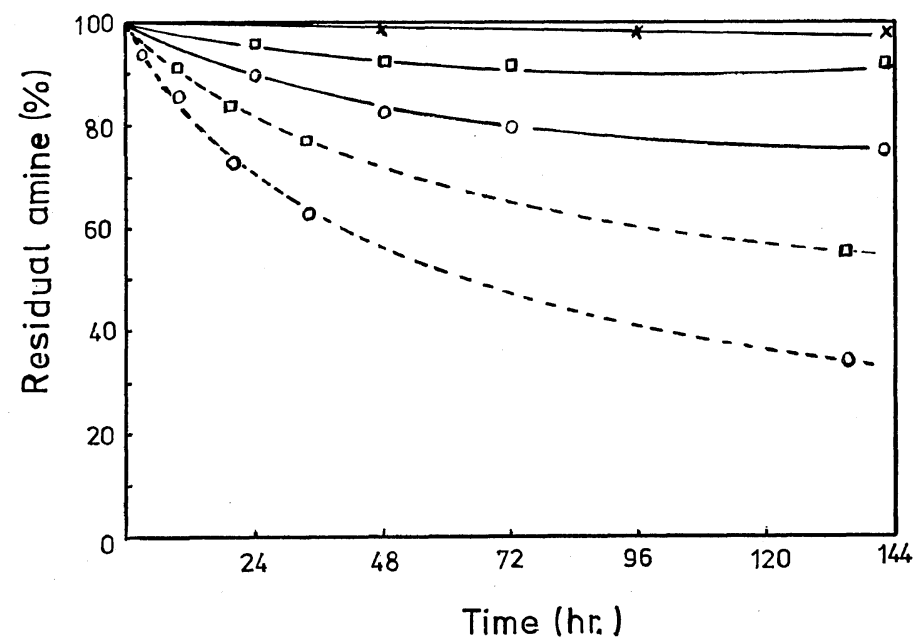

Figure 3. Condensation reactions of amines having $\beta$-hetero atoms with ethyl acetate or methyl caproate at $30^{\circ} \mathrm{C}: \bigcirc, n-\mathrm{BuNH}_{2} ; \square, \mathrm{EtOCH}_{2} \mathrm{CH}_{2} \mathrm{NH}_{2} ; \times$, $\mathrm{C}_{3} \mathrm{H}_{7} \mathrm{SCH}_{2} \mathrm{CH}_{2} \mathrm{NH}_{2}$; - , ethyl acetate; ---, methyl caproate; concn, $1 \mathrm{~mol} / \mathrm{l}$ in methanol. 
although the reactivity of $\alpha-\mathrm{N}_{2}$ was still higher than ordinary diesters such as dimethyl adipate. The enhancement effect of $\alpha$-hetero atoms on

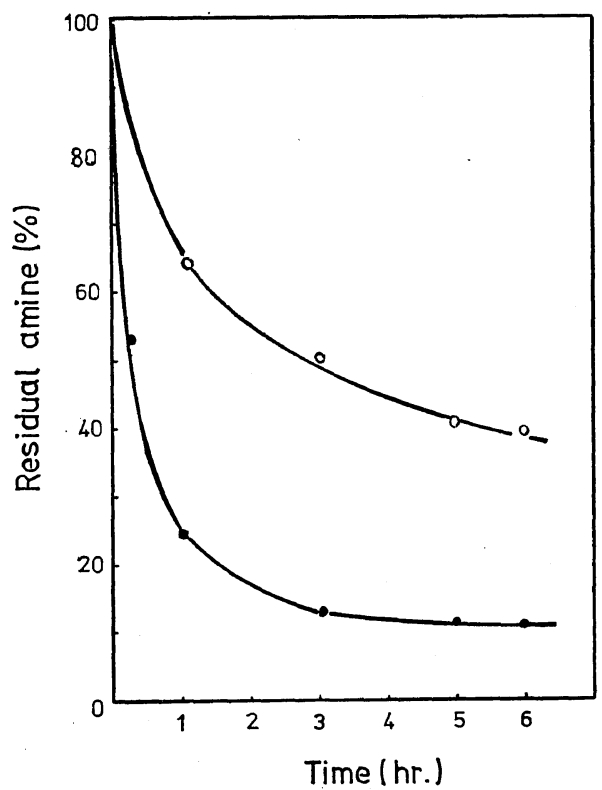

Figure 4. Polycondensation reactions of $\alpha-\mathrm{O}$ with HMD: ○, methanol; $\bigcirc$, THF; temp, $30^{\circ} \mathrm{C}$; concn, $1 \mathrm{~mol} / l$; catalyst, $\mathrm{LiOCH}_{3} 1 \mathrm{~mol} \%$.

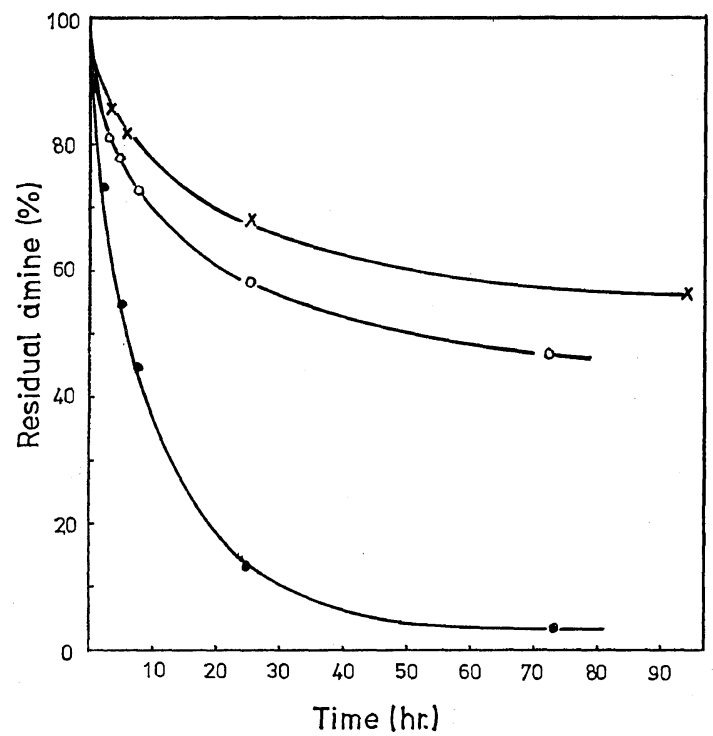

Figure 5. Polycondensation reactions of $\alpha-\mathrm{S}_{1}$ or $\alpha-\mathrm{S}_{2}$ with HMD: $\bigcirc, \alpha-\mathrm{S}_{2}$ in DMSO; $\bigcirc, \alpha-\mathrm{S}_{2}$ in THF; $\times, \alpha-\mathrm{S}_{1}$ in DMSO; temp, $30^{\circ} \mathrm{C}$; concn, $1 \mathrm{~mol} / l$; catalyst, $\mathrm{LiOCH}_{3} 1 \mathrm{~mol} \%$. the polycondensation of diesters could be arranged in the following order: $-\mathrm{O}_{-}>-\mathrm{S}->$ $-\mathrm{N}-$. This order was in close agreement with !

that of the model reaction and also with results as previously reported ${ }^{1}$ on the polycondensation of diesters having hetero atoms at position $\beta$ to the carbonyl group.

Bulk polycondensation of $\alpha-\mathrm{N}_{1}$ with HMD was carried out in sealed tubes and results are shown in Figure 7 and Table II. It is seen in Figure 7 that $\alpha-\mathrm{N}_{1}$ underwent the polycondensation with HMD more rapidly than dimethyl adipate and the reactivity enhancement due to $\alpha$ nitrogen atom was observed although the enhancement effect of $\alpha-\mathrm{N}$ was smaller than that of $\alpha-\mathrm{O}$ or $\alpha-\mathrm{S}$.

Table III summarizes properties of polyamides obtained from $\alpha-\mathrm{O}, \alpha-\mathrm{S}_{1}, \alpha-\mathrm{S}_{2}$ or $\alpha-\mathrm{N}_{2}$, where it is recognized that melting points of the resulting polyamides increased in the order of starting monomers: $\alpha-\mathrm{N}_{2}>\alpha-\mathrm{S}_{1}, \alpha-\mathrm{S}_{2}>\alpha-\mathrm{O}$.

Assuming that the polycondensation reaction of diesters with HMD proceeded in a secondorder reaction at the initial stage, apparent rate

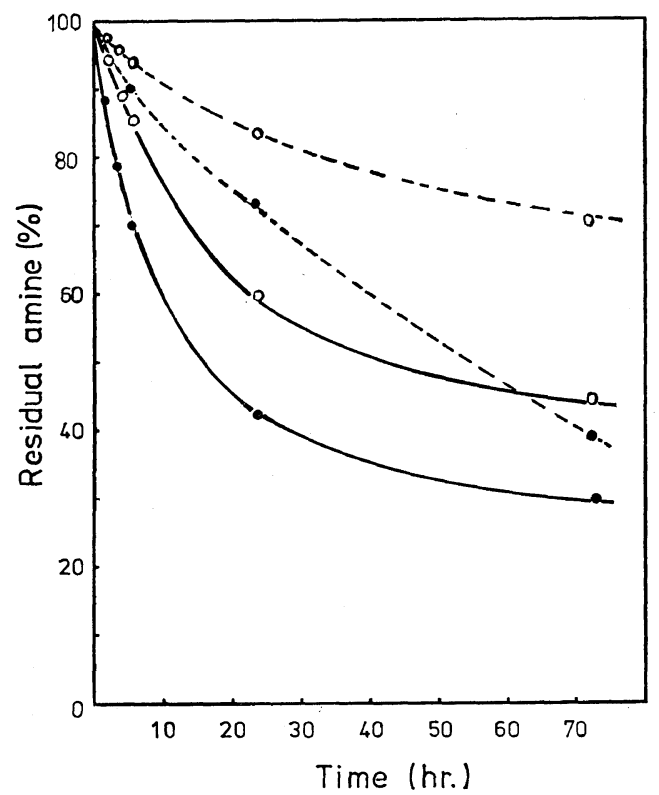

Figure 6. Polycondensation reactions of $\alpha-\mathrm{N}_{2}$ with HMD: $\bigcirc, 30^{\circ} \mathrm{C}$; $\bigcirc, 60^{\circ} \mathrm{C}$; concn, $1 \mathrm{~mol} / \mathrm{l}$; catalyst, $\mathrm{LiOCH}_{3} 1 \mathrm{~mol} \%$; -, methanol; ---, THF.

Polymer J., Vol. 6, No. 5, 1974 
Active Polycondensation

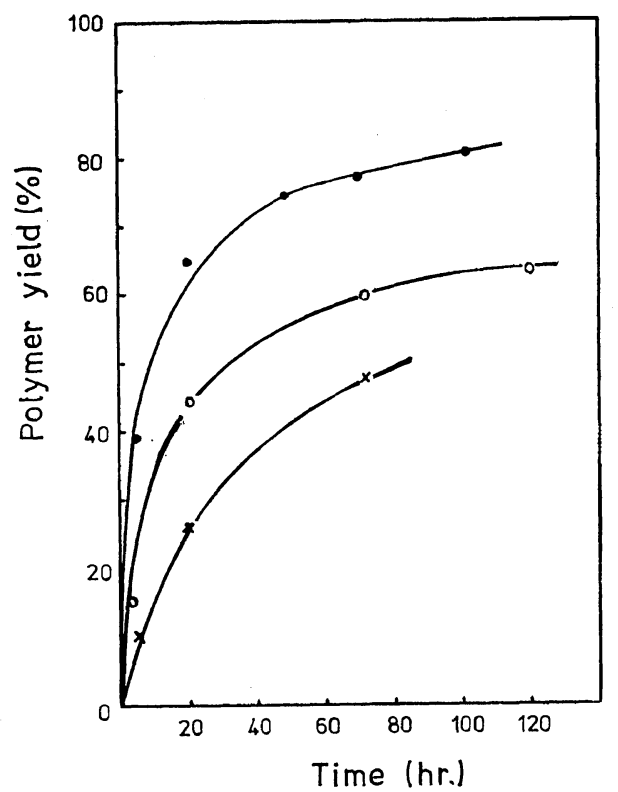

Figure 7. Bulk polycondensation of $\alpha-\mathrm{N}_{1}$ with HMD: $\bigcirc-\alpha-\mathrm{N}_{1}$ at $100^{\circ} \mathrm{C} ; \bigcirc \alpha-\mathrm{N}_{1}$ at $60^{\circ} \mathrm{C} ; \times$, dimethyl adipate at $100^{\circ} \mathrm{C}$.

constants of the polycondensation reactions were calculated and results are summarized in Table IV, where the enhancement effect of hetero atoms on the reactivity of diesters is obvious.

Infrared absorption due to the ester carbonyl group of these diesters having $\alpha$-hetero atoms appeared at around $1720 \mathrm{~cm}^{-1}$ and absorption shifts of the carbonyl group were not observed. On the other hand, NMR spectra of $\alpha-O, \alpha-S_{1}$, $\alpha-\mathrm{S}_{2}$, and $\alpha-\mathrm{N}_{1}$ which were measured in deuterated acetone by the Hitachi model R24 spectrometer $(60 \mathrm{MHz})$ using tetramethylsilane as an internal standard, exhibited a parallel result with the polycondensation reaction.

Table $\mathrm{V}$ indicates that absorptions due to $-\mathrm{OCH}_{3}$ group appeared at positions with almost the same chemical shifts, while those due to methylene protons adjacent to the carbonyl group shifted toward lower magnetic fields in the order: $\alpha-\mathrm{O}>\alpha-\mathrm{S}_{2}>\alpha-\mathrm{S}_{1}>\alpha-\mathrm{N}_{1}$. This order of chemical shifts of methylene protons coincided with the reactivity of the diesters with HMD.

The shift of the proton absorption toward a lower magnetic field is generally known to be due to a lower density of shielding electrons. It is therefore presumed that the carbonyl group
Table II. Bulk polycondensation of $\alpha-\mathrm{N}_{1}$ with HDM

\begin{tabular}{cccc}
\hline Temp, ${ }^{\circ} \mathrm{C}$ & Time, hr & Polymer yield, $\%$ & $\eta_{\mathrm{sp}} / \mathrm{c}^{\mathrm{a}}$ \\
\hline 60 & 19.5 & 44 & 0.26 \\
60 & 66 & 59 & 0.29 \\
60 & 120.5 & 63 & 0.32 \\
60 & 168 & 68 & 0.34 \\
60 & 230.5 & 69 & 0.35 \\
100 & 3 & 14 & 0.21 \\
100 & 20 & 65 & 0.33 \\
100 & 45 & 75 & 0.36 \\
100 & 70 & 75 & - \\
100 & 100 & 78 & 0.41 \\
\end{tabular}

a Measured in $96-\% \mathrm{H}_{2} \mathrm{SO}_{4}$ at $30^{\circ} \mathrm{C}$.

Table III. Properties of polyamides

\begin{tabular}{cccc}
\hline Monomer & Polymer yield, $\%$ & $\eta_{\mathrm{sp}} / \mathrm{c}$ & $\mathrm{mp},{ }^{\circ} \mathrm{C}$ \\
\hline$\alpha-\mathrm{O}$ & 100 & 0.13 & $80-90$ \\
$\alpha-\mathrm{S}_{1}$ & 40 & 0.10 & $120-126$ \\
$\alpha-\mathrm{S}_{2}$ & 100 & 0.11 & $110-118$ \\
$\alpha-\mathrm{N}_{1}$ & 78 & 0.41 & \\
$\alpha-\mathrm{N}_{2}$ & 66 & 0.29 & $154-160$ \\
\hline
\end{tabular}

Table IV. Apparent rate constants of the polycondensation

\begin{tabular}{llcc}
\hline Monomer & Solvent & Temp, ${ }^{\circ} \mathrm{C}$ & $\begin{array}{c}\text { Rate constant, } \\
l / \text { mol hr }\end{array}$ \\
\hline$\alpha-\mathrm{O}$ & MeOH & 30 & 3.00 \\
$\alpha-\mathrm{O}$ & THF & 30 & 0.54 \\
$\alpha-\mathrm{S}_{1}$ & DMSO & 30 & 0.18 \\
$\alpha-\mathrm{S}_{2}$ & DMSO & 30 & 0.33 \\
$\alpha-\mathrm{S}_{2}$ & THF & 30 & 0.08 \\
$\alpha-\mathrm{N}_{1}$ & none & 60 & 0.03 \\
$\alpha-\mathrm{N}_{2}$ & MeOH & 30 & 0.05 \\
$\alpha-\mathrm{N}_{2}$ & THF & 30 & 0.03 \\
\hline
\end{tabular}

adjacent to the methylene group becomes more electrophilic in nature by introducing hetero atoms at the position $\alpha$ to the carbonyl group, thus subject to an easy attack of nucleophiles such as amine. Another plausible explanation of the enhancement effect due to the $\alpha$-hetero atoms might be ascribed to a proximity effect of these hetero atoms for the reaction intermediate when amine is approaching the ester carbonyl group. The hetero atom at position $\alpha$ to the carbonyl group may form a hydrogen bond with the approaching amine as shown 
N. Ogata, Y. Hosoda, and G. Suzuki

Table V. Chemical shifts $\delta$ of $\mathrm{CH}_{2}$ protons of diesters having $\alpha$-heteroatoms

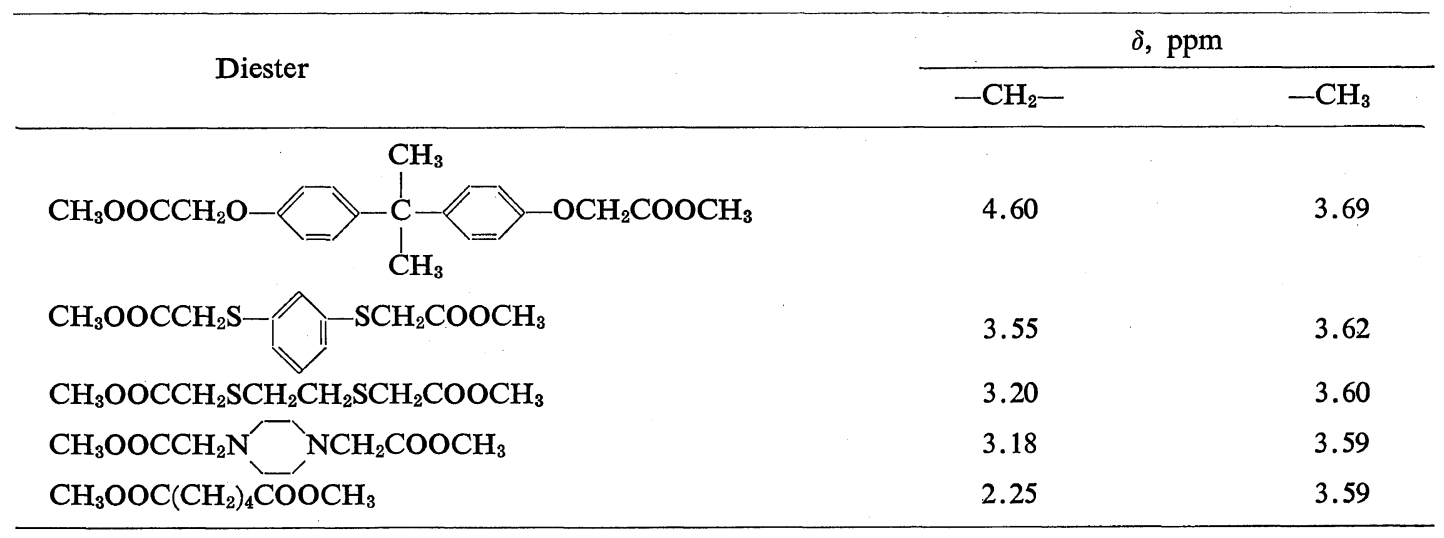

below and the hetero atom may play a role as an "anchor" to complete the condensation reaction.<smiles></smiles>

On the other hand, the introduction of hetero atoms to the amine structure rather retarded the condensation reaction. As electronegative hetero atoms reduce the basicity of the amine (as one can see by comparing the dissociation constants of piperidine $\mathrm{p} K_{\mathrm{a}}=11.22^{2}$ and morpholine $\mathrm{p} K_{\mathrm{a}}=8.36^{3}$ ), the retardation effect of the hetero atoms on the amine reactivity may be due to the decrease in basicity of amine. A stronger support based on experimental results is still necessary to explain the effect of the hetero atoms on the reactivity of esters and further studies on this problem are in progress.

\section{REFERENCES}

1. N. Ogata, K. Sanui, and K. Okouchi, Polymer J., 5, 186 (1973).

2. S. Searles, M. Tamres, F. Block, and L. A. Quarterman, J. Amer. Chem. Soc., 78, 4917 (1956).

3. H. K. Hall, Jr., ibid., 78, 2570 (1956). 